This is the author's final, peer-reviewed manuscript as accepted for publication. The publisher-formatted version may be available through the publisher's web site or your institution's library.

\title{
Sensory analysis of pet foods
}

Kadri Koppel

\section{How to cite this manuscript}

If you make reference to this version of the manuscript, use the following information:

Koppel, K. (2014). Sensory analysis of pet foods. Retrieved from http://krex.ksu.edu

\section{Published Version Information}

Citation: Koppel, K. (2014). Sensory analysis of pet foods. Journal of the Science of Food and Agriculture, 94(11), 2148-2153.

Copyright: @ 2014 Society of Chemical Industry

Digital Object Identifier (DOI): doi:10.1002/jsfa.6597

Publisher's Link: http://onlinelibrary.wiley.com/doi/10.1002/jsfa.6597/full

This item was retrieved from the K-State Research Exchange (K-REx), the institutional repository of Kansas State University. K-REx is available at http://krex.ksu.edu 


\title{
Mini-Review
}

Sensory Analysis of Pet Foods

Kadri Koppel

The Sensory Analysis Center, Kansas State University, 1310 Research Park Drive, 66502, Manhattan, KS, USA. Phone: 1-785-532-0163, E-mail: kadri@,ksu.edu.

\begin{abstract}
Pet food palatability depends on first and foremost on the pet and is related to the pet food sensory properties such as aroma, texture, and flavor. Sensory analysis of pet foods may be conducted by humans via descriptive or hedonic analysis, pets via acceptance or preference tests, and through a number of instrumental analysis methods. Sensory analysis of pet foods provides additional information on reasons behind palatable and unpalatable foods as pets lack linguistic capabilities. Furthermore, sensory analysis may be combined with other types of information such as personality and environment factors to increase understanding of acceptable pet foods. Most pet food flavor research is proprietary and, thus, there are a limited number of publications available. Funding opportunities for pet food studies would increase research and publications and this would help raise public
\end{abstract}


awareness of pet food related issues. This mini-review addresses current pet food sensory analysis literature and discusses future challenges and possibilities.

Keywords: pet, pet food, companion animal, sensory analysis, palatability

\section{Introduction}

Global production of pet foods has increased within the past years and sales in the United States alone reached 19 billion US dollars in 2012. ${ }^{1}$ Dry dog food, followed by dry cat food, wet cat food, and dog treats have the biggest shares of the total sales. Product development is intense with more than 400 food products being developed for dogs and more than 500 food products for cats in $2010 .^{2}$ According to the US pet ownership statistics, in 2011 there were more than 84 million cats and 75 million dogs in the United States alone. ${ }^{3}$ In many developed countries cats and dogs are considered more than pets, they are life companions. This humanization trend has induced development and marketing of premium brands as well as inclusion of raw ingredients and formulations that follow human food trends. ${ }^{4}$ Rapid product development is usually accompanied by research, and also publications. So far most of the research has been proprietary and the number of publications regarding pet food sensory properties research is limited.

Appearance, aroma, texture, and flavor are sensory characteristics that are important in determining pet food acceptability. Pet food flavor research has some challenges, though. Parallels can be drawn with infant food acceptability research as both infants and pets lack the linguistic capabilities to express themselves. Nevertheless pets 
are capable of influencing feeding time, quantity, and type of food served with their behavior. ${ }^{5}$ In addition just like infants have parents, pets have their owners to determine if a food is acceptable before serving. Thus researchers need to find ways to link liking or preference of pet food as perceived by the pet and owner perception of the food into a product concept and into sustained consumption by the pet. Considering the large number of companion animals, and the breeds, genders, ages, sizes, activity levels, numbers in a household, and the myriad of human family characteristics that can influence pet feeding, this task is not straightforward. However, sensory analysis methods can help in understanding pet and owner behavior and pet food selection by providing additional information to pet food manufacturers and animal scientists.

Sensory analysis has two main types of methods: analytical (descriptive and discrimination) and consumer (acceptance, preference, consumption, and qualitative testing). ${ }^{6-7}$ Pet food appearance, aroma, flavor, and texture can be characterized using humans and instruments, while preference or consumption can be measured using either animals or humans (Fig. 1). More specifically, human sensory analysis can include description of sensory properties or acceptance or preference testing by pet owners, and food or attitude-related testing through questionnaires. Analysis by pets is usually focused on choice, consumption, or behavioral characteristics of the pet before, during, and after eating.

The use of humans has obvious limitations because human taste and flavor perception is different from that of a dog or cat. ${ }^{8-9}$ For example cats are considered not able to taste most carbohydrates as sweet ${ }^{10}$, while the similarity or difference in responses 
to L- $\alpha$-amino acid solutions depend on the amino acid ${ }^{11}$; both dogs and cats are considered carnivores and this underlines the importance of meat flavor and umami taste to them. Further comparisons among species have been detailed elsewhere. ${ }^{12-13}$ The importance of olfactory sense was demonstrated by Houpt et al. ${ }^{14}$ who showed that food odor needs to be paired with food flavor in order for the food to be continuously accepted. According to Neufeld ${ }^{15}$ olfactory sense of cats and dogs is more advanced than the one of humans, while taste perception has developed further in humans. In addition, Griffin ${ }^{16}$ stresses the importance of tactile stimuli and mouthfeel perception (i.e. texture) in understanding pet food palatability or acceptance by animals. Although some aspects of perception may be different, descriptive sensory information from humans may be helpful in understanding pet food acceptance or rejection by both humans and pets. Instrumental analysis, such as gas chromatography mass spectroscopy and high pressure liquid chromatography, electronic noses and tongues; other methods to measure volatile compounds, acids, sugars, peptides and protein analysis; and instrumental texture analysis are available to aid in sensory research. This mini-review addresses current pet food sensory analysis literature and discusses future challenges and possibilities.

\section{Sensory Analysis of Pet Foods}

Descriptive sensory analysis

Descriptive sensory analysis of pet foods describes product appearance, aroma, texture, and flavor characteristics and measures the intensity of these characteristics on a scale. Descriptive sensory analysis information can be used in combination with other 
types of information about the product, such as ingredients, processing, or palatability data to explain effects of ingredients or processing on flavor or texture. Descriptive sensory analysis can be used for different purposes from marketing research to developing new products, or for quality control. Descriptive sensory analysis of pet foods has been limited. Lin et al. ${ }^{17}$ studied lipids and processing conditions effects on sensory aromatic and appearance characteristics of extruded pet food. These authors found a correlation between pet food appearance and fat content. Furthermore these authors found that fat content and source had an effect on the intensity of fatty, painty, and cardboard odors as well as texture characteristic oily surface.

In 1999 Denis et al. looked at twelve moist cat foods and tried to determine relationships among sensory aroma and appearance attributes, gas chromatography (GC), texture, gas sensor measurements, and palatability. ${ }^{18}$ These authors found that although sensory analysis predicts palatability better than some instrumental measurements, because of time and cost related to conducting a descriptive sensory panel analyses, instruments may provide a faster option for the pet food industry.

Both Denis et al. ${ }^{18}$ and Lin et al. ${ }^{17}$ only looked at aroma properties of pet foods. This can be understood from a pet owner standpoint: pet food needs to look and smell acceptable as the owner prepares dry or canned food to the pet. Other studies ${ }^{19-21}$ have also included flavor analysis in pet food research. According to Di Donfrancesco et al. ${ }^{21}$ aroma attributes don't necessarily predict flavor characteristics of the product. This is important as pets make the initial decision to eat based on aroma, but continue eating only if flavor of the food is delivered as promised by the aromatics. ${ }^{14}$ 
Two studies were conducted by Pickering in 2009 on dry and wet cat foods. ${ }^{19-20}$ This author focused on both aromatic and flavor attributes of the foods and found that sensory analysis could be a useful tool in enhancing understanding of cat food flavor properties. Furthermore this author suggested both wet and dry cat foods are highly complex in flavor characteristics. A similar conclusion was reached by Di Donfrancesco et al., who studied dry dog foods and developed a sensory lexicon that included more than 70 appearance, aroma, flavor, and texture attributes by analyzing 21 commercial products. ${ }^{21}$ According to the list of attributes used in descriptive studies (Table 1-3), pet foods are not simple products when it comes to flavor characteristics. Attributes that were used in two or more studies were: overall color or lightness, size uniformity, oily, size, and surface roughness or smoothness for appearance; burnt, cardboard, caramel, chicken, cooked, fish, grain or cereal, liver, meaty, metallic, methionine, offaly, oxidized oil or painty, prawn, pungent, rancid or oxidized, soy, spice, vegetable, vitamin, bitter, salty, sour, and sweet for odor and flavor attributes; cohesiveness, firmness, fracturability or brittleness, gritty, and hardness for texture attributes. Although main vocabulary seems to exist for description of pet foods, there is ample room for further studies to look at the specific effects of processing, such as extrusion and baking, packaging, ingredient effects, and formulation on sensory characteristics. Furthermore, sensory studies should aim at explaining acceptability, and palatability based on sensory analysis and instrumental measurements. 


\section{Consumer studies}

\section{Owners}

Information from the pet owner or the pet, or both can be collected during consumer studies related to pet food. Consumer studies provide additional understanding of pet food selection as well as explain acceptability and preference issues. A decision to purchase a pet product often is made on the packaging and marketing claims; repurchase depends on the delivered product experience that is related to the sensory properties, such as the pet's breath smells fresher to the owner after consuming a dental treat.

Most pet-related consumer studies have been conducted via questionnaires and typically inquire about income, age, level of education, living area, number of pets, and relationships about pets. ${ }^{22}$ Tesfom and Birch $^{23}$ conducted a study about pet food shopping behavior and tried to relate this behavior back to human food shopping behavior. These authors found that dog owners are more worried about buying healthy food for their dogs than for themselves. In addition they found dog owners to be more loyal to dog food brands than they would be with human foods.

Some consumer studies have addressed the issues of overweight dogs and cats through their owners. Bland et al. ${ }^{24}$ looked at dog feeding frequencies among Australian households and found that overweight dogs would get treats significantly more often than normal weight dogs would. In addition they found a correlation between pets being overweight and frequency of exercise. Another study by Suarez et al. ${ }^{25}$ studied owners of overweight dogs in their selection of pet food. These authors found that owners of overweight dogs had less interest in the nutritional quality of their pet's food and were 
more prone to special offers of commercial dog food than the owners of normal weight dogs. Nijland et al. ${ }^{26}$ looked at overweight dogs and cats in the Netherlands and tried to determine if animal obesity is related to owner obesity. These authors found that overweight dogs are likely to have overweight owners. This association was not proven for cats, though. This may depend on the age of the owner, as a different study conducted by Heuberger and Wakshlag ${ }^{27}$ determined that cats of older people were more likely to be overweight than younger cat owners.

Another questionnaire study used photos of pet food products to acquire about importance of brand, type (canned or dry), price, and owner's idea of pet preference to the pet owners in Thailand. ${ }^{28}$ This study found that the brand of dog food, followed by what the pet would prefer were the main factors to the pet owner. A study comparing home use test and laboratory animal preference found that home pets had considerable variation in their liking towards the three different foods according to their owners' ratings. ${ }^{29}$ Considering this, future studies may be of interest to measure actual animal liking of food and owner perception of animal liking of food in home conditions. Furthermore, no studies were found that would go beyond a questionnaire study to measure importance of odor or appearance of actual pet foods to pet owners.

\section{Pets and Palatability}

Palatability is defined as pleasantness of taste of feed to animals and is understood through the sensory characteristics of food, such as taste, flavor, and mouthfeel. ${ }^{9,16}$ Typical methods for palatability measurement among dogs and cats include preference and 
acceptability testing. Preference implies that a choice is to be made between sample foods and this is typically conducted using a two-bowl test. ${ }^{16}$ Important factors in this test include first choice - which sample is sniffed or tasted first, amount of food consumed, and intake ratio (calculated as a ratio of one food consumed over sum of both foods consumed). One-bowl test is used to measure acceptability of a food sample. Important factors would include amount consumed as well as intake ratio in case several foods are compared using a consecutive feeding plan. The two-bowl test would often be conducted using kennel or laboratory dogs or cats, while the one-bowl test is more suitable for the home environment during an in-house testing.

\section{Preference and Acceptability}

Food preferences of dogs and cats and any determining factors that would influence preferences have been extensively described elsewhere. ${ }^{14,30-38}$ Most authors speculate about cat preferences based on the knowledge of tasting capabilities and historic background (carnivores) of cats, while limited research is available on ingredient and texture preferences. For example in fat type preference, cats would prefer bleached tallow over chicken fat or butter, while $25 \%$ of fat content was preferred over $10 \%$ and $50 \%{ }^{39}$ Furthermore, according to MacDonald et $a .^{40}$ cats find medium-chain fatty acids unpalatable. Texture importance was shown by Hullar et al. ${ }^{41}$ Those authors found that when extruded, diets that contain vegetable ingredients become more palatable. No orderof-preference of different types of meats is available for cats as it is for dogs. According to Lohse $^{42}$, dog preference for different meats is beef $>$ lamb $>$ chicken $>$ horsemeat (when 
served as fresh cubes) and according to Houpt and Hintz ${ }^{33}$ beef $=$ pork $>$ lamb $=$ chicken $>$ horsemeat (when served as cooked ground meat). In addition dogs would prefer canned or cooked meats over fresh ones. ${ }^{42}$ Some studies have reported ingredient and processing effects, such as soybean usage $e^{43-44}$, spent hen meal usage ${ }^{45}$, moisture level effect ${ }^{46}$, and use of enzymes such as carbohydrases ${ }^{44}$ on palatability of foods in dogs and cats. Most often these types of studies would relate palatability to digestibility and quality characteristics of the pet foods, but not to sensory characteristics or actual consumer attitudes or preferences.

Food preferences have been associated to environmental factors such as early feeding experiences and neonatal development. ${ }^{47-48}$ Neophobia, the dislike to try new foods may be directly associated to young animal experiences and affects cat and dog food acceptability. ${ }^{49}$ Other environmental factors such as living conditions, number and age of people living in a household, other pets in household, should be considered. Preferences of animals housed in kennels or free-ranging farm animals and animals who live at home are usually different. ${ }^{35}$ Few studies have even linked family characteristics and palatability $\operatorname{aspects}^{50,29}$ and have tried to relate owner personality to selection of companion animal breed or type. $^{51-52}$ Furthermore, van den Bos et al. looked at cat body language and behavior characteristics as a predictor of palatability. ${ }^{53}$ According to some studies cats and dogs are able to balance their diets based on nutritional composition ${ }^{54-56}$, thus nutrients in companion animal food that are detected based on their sensory properties should not be overlooked. It is likely that acceptability of a food is determined based on a combination 
of factors presented here, and this presents a challenge for future studies in pet food research.

Small number of animals tested and considerable variation within the results are typical palatability testing limitations. It is common to divide animals into groups based on their gender, age, or weight, but not look beyond these characteristics. Furthermore, in preference testing (2-bowl test) and in acceptability testing (1-bowl test) the animal performing the test may not have other food choices other than the ones presented and thus may be forced to eat a food even if they find it less palatable. It seems other explanations beyond the ones explored should be sought in explaining animal preferences and these may include sensory characteristics such as flavor and texture of the foods, but also animal character, family type, and other factors may have a role in determining preferences. Using a larger number of animals would increase the costs of testing, but would also provide possibilities of clustering animals into different liking groups.

\section{Instrumental flavor studies}

As with human foods, flavor characteristics can be measured using instrumental means in pet foods. Few studies have looked at pet food composition from a flavor perspective, though. In a study of moist cat foods several measurement types, such as electronic nose, sensory characteristics, volatile compounds, texture parameters, and palatability were used to find correlations. ${ }^{18}$ Those authors found that although sensory evaluation and volatile compounds predicted preference better, electronic nose measurements were faster and easier to conduct. Oladipupo et al. looked at electronic nose and electronic tongue in 
relation to palatability and found good correlation among those as well as potential of these methods for use in quality control. ${ }^{57}$ Limitations to the use of electronic tongue and nose include providing a profile fingerprint of the flavor or aromatic characteristics of the pet food that may be difficult to understand in terms of actual sensory properties. Another study looked at volatile compounds and sensory characteristics of dry dog foods. ${ }^{58}$ Those authors found that dry dog foods are complex products and that a more defined sample set would help pinpoint relationships among volatiles and sensory attributes. Limitations of using volatile compounds measurement systems such as GC-MS and GC-O include differences in perception of a single volatile and a combination of volatiles and have been reviewed elsewhere. ${ }^{59}$ Texture research has looked at behavioral characteristics such as kibble grasping and biting and related this into instrumental measurements; kibble shape and size are important factors for palatability as cat and dog muzzle sizes and shapes determine which kibbles are easier to ingest but may also help with applications such as dental hygiene. ${ }^{60}$ As sensory analysis of pet foods performed by humans is often complicated and expensive to conduct, further studies relating animal acceptability, sensory characteristics, and instrumental measurements of appearance, taste, flavor, texture, and quality are of interest.

\section{Future challenges and opportunities}

Pet food products such as balanced dry food, canned food, as well as snacks and treats are abundantly available in the marketplace. The success of those products comes down to the companion animal - cat or dog - accepting the product as palatable. This is complemented 
by owner perception, as the owner purchases and offers the product to their pet as well as a myriad of other factors that all influence palatability. So far pet food sensory analysis has not dealt with in-depth analysis of reasons for acceptability and has focused more on palatability testing that often provides limited information. In addition most research seems to be proprietary. Future research opportunities are abundant in looking at ingredient or processing effects on sensory characteristics of pet foods, as well as determining liking based on characterizing the surrounding environment, behavior, and character of the companion animal.

\section{References}

1. Pet Food Institute. Pet Food Sales. Available at: http://www.petfoodinstitute.org/?page=PetFoodSales. Accessed: 13 November, 2013.

2. Petfood Industry. Petfood top 10: riding out the storm. Available at: http://www.petfoodindustry.com/Petfood_top_10_Riding_out_the_storm.html. Accessed: 13 November, 2013.

3. Pet Food Institute. Pet Food Sales. Available at: http://www.petfoodinstitute.org/?page=PetPopulation. Accessed: 13 November, 2013.

4. Euromonitor International. Pet care in France. Available at: http://www.euromonitor.com/pet-care-in-france/report. Accessed: 13 November, 2013. 
5. Day JEL, Kergoat S, Kotrschal K, Do pets influence the quantity and choice of food offered to them by their owners: lessons from other animals and the pre-verbal human infant. CAB Reviews: Perspectives in Agriculture, Veterinary Science, Nutrition and Natural Resources 4: 1-12 (2009).

6. Lawless HT, Heymann H, Sensory evaluation of foods: principles and practices. $2^{\text {nd }}$ ed. Chapman\&Hall, New York NY, USA, pp. 1-18, 125-148 (2010).

7. Meilgaard M, Civille GV, Carr BT, Advanced statistical methods. Sensory Evaluation Techniques. 4th Ed.CRC Press, Boca Raton, FL, USA, pp. 173-186, 255-309 (2006).

8. Chaudhari N, Roper SD, The cell biology of taste. J Cell Biol 190(3): 285-296 (2010).

9. Thorne C, The Waltham book of dog and cat behavior. $2^{\text {nd }}$ Ed. Pergamon Press, Oxford, England. Pp 44-48, 115 (1992).

10. Li X, Li W, Wang H, Bayley DL, Cao J, Reed DR, Bachmanov AA, Huang L, Legrand-Defretin V, Beauchamp GK, Brand JG, Cats lack a sweet taste receptor. J Nutr 136: 1932S-1934S (2006).

11. Boudreau JC, Cat and human taste responses to L-a-amino acid solutions. Flavor of Foods and Beverages 231-246 (1978).

12. Boudreau JC, Neurophysiology and human taste sensations. J Sens Stud 1: 185-202 (1986). 
13. Boudreau JC, Sivakumar L, Do LT, White TD, Oravec J, Hoang NK, Neurophysiology of geniculate ganglion (facial nerve) taste systems: species comparisons. Chem Senses 10(1): 89-127 (1985).

14. Houpt KA, Hintz HF, Shepherd P, The role of olfaction in canine food preferences. Chem Sens Flav 3(3): 281-290 (1978).

15. Neufeld K, Synergies of different flavours for dog and cat food: olfactory sense better developed. Kraftfutter 3-4 (2012).

16. Griffin RW, Section IV: Palatability. Petfood Technology, 1st ed. Kvamme, J.L, Phillips, T.D. Publisher: Watt Publishing Co., Mt. Morris, IL, USA, pp. 176-193 (2003).

17. Lin S, Hsieh F, Heymann H, Huff HE, Effects of lipids and processing conditions on the sensory characteristics of extruded dry pet food. J Food Qual 21: 265-284 (1998).

18. Denis N-SC, Carel P, Hossenlopp J, Trystram G, Rutledge DN, Emonet C, Correlation between sensory data, instrumental data (gas sensors, physic-chemical analysis) and palatability measurements of twelve moist foods for cats. Sci Aliment, 19(1): 35-55 (1999).

19. Pickering GJ, Optimizing the sensory characteristics and acceptance of canned cat food: use of a human taste panel. J Anim Physiol Anim Nutr 93: 52-60 (2009).

20. Pickering GJ, Optimisation of dried cat food using a human taste panel: methodology and characterization of flavor. Food Aust 61(1-2): 30-36 (2009). 
21. Di Donfrancesco B, Koppel K, Chambers EIV, An initial lexicon for sensory properties of dry dog food. J Sens Stud 27: 498-510 (2012).

22. Merle $\mathrm{C}$, What pet owners really think. Proceedings of the North Amrican Veterinary Conference, Vet Tech 249 (2009).

23. Tesfom G, Birch N, Do they buy for their dogs the way they buy for themselves? Psychol Market 27(9): 898-912 (2010).

24. Bland IM, Guthrie-Jones A, Taylor RD, Hill J, Dog obesity: owner attitudes and behavior. Prev Vet Med 92: 333-340 (2009).

25. Suarez L, Pena C, Carreton E, Juste MC, Bautista-Castano I, Montoya-Alonso JA, Preferences of owners of overweight dogs when buying commercial pet food. $J$ Anim Physiol N 96: 655-659 (2012).

26. Nijland ML, Stam F, Seidell JC, Overweight in dogs, but not in cats, is related to overweight in their owners. Public Health Nutr 13(1): 102-106 (2009).

27. Heuberger R, Wakshlag J, Characteristics of ageing pets and their owners: dogs v. cats. Brit J Nutr 106: S150-S153 (2011).

28. Tengpongsathon K, Phaosathienpan S, Application of analytical hierarchy process for consumer preference on pet food product in Thailand. International Symposium on Technology for Sustainability. Bangkok, Thailand, November 21-24 (2012).

29. Smith SL, Kronfeld DS, Banta CA, Owner's perception of food flavor preferences of pet dogs in relation to measured preferences of laboratory dogs. Appl Anim Ethol 10: 75-87 (1983).

30. Watson T, Palatability: feline food preferences. Vet Times 41(21): 6-10 (2011). 
31. Bradshaw JWS, Sensory and experiential factors in the design of foods for domestic dogs and cats. Proceedings of the Nutrition Society 50: 99-106 (1991).

32. Zaghini G, Biagi G, Nutritional peculiarities and diet palatability in the cat. Vet Res Comm 29: 39-44 (2005).

33. Houpt KA, Hintz H, Palatability and canine food preferences. Canine Pract 5(6): 29-35 (1978).

34. Thorne CJ, Feeding behavior in the cat - recent advances. J Small Anim Pract 23(9): 555-562 (1982).

35. Bradshaw JWS, The evolutionary basis for the feeding behavior of domestic dogs (Canis familiaris) and cats (Felis catus). J Nutr 136: 1927S-1931S (2006).

36. Bourgeois H, Understanding how cats eat - applied research into palatability. Waltham Focus 13(3): 24-26 (2003).

37. Kane E, Feeding behavior of the cat. Nutrition of the dog and cat. Waltham Symposium 7: 147-158 (1985).

38. Houpt KA, Smith SL, Taste preferences and their relation to obesity in dogs and cats. Canadian Vet J 22: 77-81 (1981).

39. Kane E, Morris JG, Rogers QR, Acceptability and digestibility by adult cats of diets made with various sources and levels of fat. J Anim Sci 53(6): 1516-1523 (1981).

40. MacDonald ML, Rogers QR, Morris JG, Aversion of the cat to dietary mediumchain triglycerides and caprylic acid. Physiol Behav 35(3): 371-375 (1985). 
41. Hullar I, Fekete S, Szocs Z, Effect of extrusion on the quality of soybean-based catfood. J Anim Physiol A Anim Nutr 80: 201-206 (1998).

42. Lohse CL, Preferences of dogs for various meats. J Am Anim Hosp Assoc 10(2): 187-192 (1974).

43. Cavalieri Carciofi A, Domingues de Oliveira LD, Valerio AG, Longo Borges L, Carvalho FM, Brunetto MA, Souza Vasconcellos R, Comparison of micronized whole soybeans to common protein sources in dry dog and cat diets. Anim Feed Sci Tech 151: 251-260 (2009).

44. Felix AP, Carvalho MP, Alarca LG, Brito CBM, Oliveira SG, Maiorka A, Effects of the inclusion of carbohydrases and different soybean meals in the diet on palatability, digestibility, and faecal characteristics in dogs. Anim Feed Sci Tech 174: $182-189$ (2012).

45. Rajendra Kumar K, Kulkarni VV, Chandirasekaran V, Preparation, storage stability and palatability of dry rendered spent hen meal based dog pet food. Indian $J$ Poultry Sci 46(1): 83-88 (2011).

46. De Brito CBN, Felix AP, de Jesus RM, de Franca MI, de Oliveira SG, Krabbe EL, Maiorka A, Digestibility and palatability of dog foods containing different moisture levels, and the inclusion of a mould inhibitor. Anim Feed Sci Tech 159: 150-155 (2010).

47. Hepper PG, Wells DL, Millsopp S, Kraehenbuehl K, Lyn, SA, Maurouz O, Prenatal and early sucking influences on dietary preference in newborn, weaning, and young adult cats. Chem Senses 37: 755-766 (2012). 
48. Stasiak M, The effect of early specific feeding on food conditioning in cats. Dev Psychobiol 39: 207-215 (2001).

49. Bradshaw JWS, Mere exposure reduces cats neophobia to unfamiliar food. Anim Beh 34(2): 613-614 (1986).

50. Griffin RW, Scott GC, Cante CJ, Food preferences of dogs housed in testingkennels and in consumers' homes: some comparisons. Neurosci Biobehav R 8: 253259 (1984).

51. Hergovich A, Mauerer I, Riemer V, Exotic animal companions and the personality of their owners. Anthrozoos 24(3): 317-327 (2011).

52. Wells DL, Hepper PG, The personality of "aggressive" and "non-aggressive" dog owners. Pers Indiv Differ 53: 770-773 (2012).

53. Van den Bos R, Meijer MK, Spruijt BM, Taste reactivity patterns in domestic cats (Felis silvestris catus). Appl Anim Beh Sci 69: 149-168 (2000).

54. Kane E, Feeding behavior of the cat. Nutrition of the Dog and the Cat. Waltham Symposium 7: 147-158 (1989).

55. Torres CL, Hickenbottom SJ, Rogers QR, Palatability affects the percentage of metabolizable energy as protein selected by adult beagles. J Nutr 3516-3522 (2003).

56. Hewson-Hughes AK, Hewson-Hughes VL, Miller AT, Hall SR, Simpson SJ, Raubenheimer D, Geometric analysis of macronutrient selection in the adult domestic cat, Felis catus. J Exp Biol 214: 1039-1051 (2011).

57. Oladipupo B, Stough J, Guthrie N, Application of Combined Electronic Nose and 
Tongue Technology in Petfood Flavor Development and Quality Control. 14th International Symposium on Olfaction and Electronic Nose Proceeding. 1362, p. 75-76 (2011).

58. Koppel K, Adhikari K, Di Donfrancesco B, Volatile compounds in dry dog foods and their influence on sensory aromatic profile. Molecules 18: 2646-2662 (2013).

59. Chambers EIV, Koppel K, Associations of Volatile Compounds with Sensory Aroma and Flavor: The Complex Nature of Flavor. Molecules 18: 5, 4887-4905 (2013).

60. Bourgeois $\mathrm{H}$, Understanding how cats eat - applied research into palatability. Waltham Focus 13 (3) 24-26 (2003). 
Figure 1. Pet food sensory analysis research methods. 
Table 1. Appearance attributes used in descriptive sensory analysis of pet foods.

\begin{tabular}{|l|l|l|l|l|}
\hline \multicolumn{1}{|c|}{ Attribute } & \multicolumn{1}{|c|}{ Definition } & \multicolumn{1}{c|}{$\begin{array}{c}\text { Reference } \\
\text { standard }\end{array}$} & Reference \\
\hline Brown color & DD & Yes & Yes & 21 \\
\hline Green color & DD & Yes & Yes & 21 \\
\hline Overall color, lightness & WC, PF & No & No & $17-18$ \\
\hline Red Brown color & DD & Yes & Yes & 21 \\
\hline Yellow-red color & WC & No & No & 18 \\
\hline Color uniformity & DD & Yes & Yes & 21 \\
\hline Contrast & WC & No & No & 18 \\
\hline Shape uniformity & DD & Yes & Yes & 21 \\
\hline Size uniformity & DD, WC & Yes & Yes & 17,21 \\
\hline Fibrous & DD & Yes & Yes & 21 \\
\hline Flecks & DD & Yes & Yes & 21 \\
\hline Grainy & DD & Yes & Yes & 21 \\
\hline Oily & DD, PF & Yes & Yes & 17,21 \\
\hline Porous & DD & Yes & Yes & 21 \\
\hline Shape & DD & Yes & Yes & 21 \\
\hline Size & DD, WC & Yes & Yes & 18,21 \\
\hline Starchy & DD & Yes & Yes & 21 \\
\hline $\begin{array}{l}\text { Surface } \\
\text { smoothness roughness, }\end{array}$ & DD, PF & Yes & Yes & 17,21 \\
\hline Wet moist & DD & Yes & Yes & 21 \\
\hline Quantity of pieces & WC & No & 18 \\
\hline DD - & No & \\
\hline
\end{tabular}

DD - dry dog food; WC - wet cat food; DC - dry cat food; PF - pet food. 
Table 2a. Aroma and flavor attributes used in descriptive sensory analysis of pet foods.

\begin{tabular}{|c|c|c|c|c|}
\hline Attribute & Food type & Definition & $\begin{array}{l}\text { Reference } \\
\text { standard }\end{array}$ & Reference \\
\hline Ashy & DD & Yes & Yes & 21 \\
\hline Bacon & DC & No & Yes & 20 \\
\hline Barnyard & DD & Yes & Yes & 21 \\
\hline Boiled & WC & No & No & 18 \\
\hline Brothy & DD & Yes & Yes & 21 \\
\hline Brown & DD & Yes & Yes & 21 \\
\hline Bread crust & DC & No & Yes & 20 \\
\hline Burnt & DD, WC, DC & Yes & Yes & \begin{tabular}{|l|}
$19-21$ \\
\end{tabular} \\
\hline Cardboard & DD, PF & Yes & Yes & 17,21 \\
\hline Caramel & WC, DC & No & Yes & $18-20$ \\
\hline Carrot (raw) & \begin{tabular}{|l|} 
DD \\
\end{tabular} & Yes & Yes & 21 \\
\hline Celery & DD & Yes & Yes & 21 \\
\hline Chicken, Poultry & WC, DC & No & Yes & $18-20$ \\
\hline Clove & DD & Yes & Yes & 21 \\
\hline Cooked & DD, WC & Yes & Yes & 18,21 \\
\hline Degraded & WC & No & No & 18 \\
\hline Dusty/earthy & DD & Yes & Yes & 21 \\
\hline Earthy & DD & Yes & Yes & 21 \\
\hline Egg & DD & Yes & Yes & 21 \\
\hline Fermented & DD & Yes & Yes & 21 \\
\hline Fatty & PF & Yes & No & 17 \\
\hline Fish, Tuna & DD, WC, DC & \begin{tabular}{|c|} 
Yes \\
\end{tabular} & Yes & $18-21$ \\
\hline Garlic & DD & Yes & Yes & 21 \\
\hline Grain, Cereal & DD, WC, DC, PF & Yes & Yes & $17-21$ \\
\hline Hay-like & DD & Yes & Yes & 21 \\
\hline Herbal & WC & Yes & Yes & 19 \\
\hline Herb, fresh & $\mathrm{DC}$ & No & Yes & 20 \\
\hline Herb, dry & DC & No & Yes & 20 \\
\hline Liver & DD, WC & Yes & Yes & 18,21 \\
\hline Meaty & DD, WC, DC & Yes & Yes & $18-21$ \\
\hline Metallic & $\mathrm{DD}, \mathrm{WC}$ & Yes & Yes & 18,21 \\
\hline Methionine & \begin{tabular}{|l} 
WC, DC \\
\end{tabular} & No & Yes & 19,20 \\
\hline Musty/dusty & DD & Yes & Yes & 21 \\
\hline Musty & DD & Yes & Yes & 21 \\
\hline Offaly & WC, DC & No & Yes & 19,20 \\
\hline Oily & DD & Yes & Yes & 21 \\
\hline Onion & DD & Yes & Yes & 21 \\
\hline Overall intensity & WC & No & No & 18 \\
\hline Oxidized Oil, Painty & $\mathrm{DD}, \mathrm{PF}$ & Yes & Yes & 17,21 \\
\hline Pepper, black & DD & Yes & Yes & 21 \\
\hline Persistent & WC & No & No & 18 \\
\hline Plastic & DD & Yes & Yes & 21 \\
\hline Prawn & WC, DC & No & Yes & 19,20 \\
\hline Pungent & DD, WC & Yes & Yes & 18,21 \\
\hline Rancid, Oxidized & WC, DC & No & Yes & $18-20$ \\
\hline Smoky & DD & Yes & Yes & 21 \\
\hline Soy & DD, WC, DC & Yes & Yes & $19-21$ \\
\hline Spice (complex) & DD, WC, DC & Yes & Yes & $18-21$ \\
\hline Brown Spice & DD & Yes & Yes & 21 \\
\hline Stale & DD & Yes & Yes & 21 \\
\hline Starchy & DD & Yes & Yes & 21 \\
\hline Straw-like & DD & Yes & Yes & 21 \\
\hline
\end{tabular}

DD - dry dog food; WC - wet cat food; DC - dry cat food; PF - pet food. 
Table $2 \mathrm{~b}$. Aroma and flavor attributes used in descriptive sensory analysis of pet foods.

\begin{tabular}{|l|l|l|l|l|}
\hline Attribute & Food type & Definition & $\begin{array}{l}\text { Reference } \\
\text { standard }\end{array}$ & Reference \\
\hline Toasted & DD & Yes & Yes & 21 \\
\hline Vegetable (complex) & DD, WC & Yes & Yes & $18,19,21$ \\
\hline Vegemite & DC & No & Yes & 20 \\
\hline Vitamin & DD & Yes & Yes & $19-21$ \\
\hline Bitter & DD, WC, DC & Yes & Yes & $19-21$ \\
\hline Salt & DD, WC, DC & Yes & Yes & $19-21$ \\
\hline Sour & DD, WC, DC & Yes & Yes & $19-21$ \\
\hline Sweet & DD, WC & Yes & Yes & 19,21 \\
\hline
\end{tabular}

DD - dry dog food; WC - wet cat food; DC - dry cat food; PF - pet food. 
Table 3. Texture attributes used in descriptive sensory analysis of pet foods.

\begin{tabular}{|l|l|l|l|l|}
\hline Attribute & Food type & Definition & $\begin{array}{l}\text { Reference } \\
\text { standard }\end{array}$ & Reference \\
\hline Adhesion* & WC & No & No & 18 \\
\hline Cohesiveness of mass* & DD, WC & Yes & Yes & 18,21 \\
\hline Chewiness & WC & No & Yes & 19 \\
\hline Fiberous & DD & Yes & Yes & 21 \\
\hline Firmness & DD, WC & Yes & Yes & 18,21 \\
\hline $\begin{array}{l}\text { Fracturability, } \\
\text { Brittleness }\end{array}$ & DD, DC & Yes & Yes & $20-21$ \\
\hline Graininess & & Yes & Yes & 21 \\
\hline Gritty & DD & Yes & Yes & $19-21$ \\
\hline Hardness & DD, WC, DC & Yes & Yes & $19-21$ \\
\hline Initial crispness & DD, WC, DC & Yes & Yes & 21 \\
\hline Mouthcoat & DD & Yes & Yes & 21 \\
\hline Oily mouthfeel & DD & Yes & Yes & 21 \\
\hline Roughness & DD & Yes & Yes & 20 \\
\hline Powdery & DC & Yes & Yes & 21 \\
\hline Springiness & DD & No & Yes & 21 \\
\hline Viscosity & DD & Yes & 19 \\
\hline
\end{tabular}

*evaluated visually with fork; DD - dry dog food; WC - wet cat food; DC - dry cat food; PF - pet food. 